\title{
DINÂMICAS DE RISCOS E CRISES EM CON- TEXTOS DE (IN)VISIBILIDADE NAS MÍDIAS SOCIAIS
}

\author{
DIEGO WANDER DA SILVA \\ PONTIFÍCIA UNIVERSIDADE CATÓLICA DO RIO GRANDE DO SUL \\ PORTO ALEGRE, RIO GRANDE DO SUL, BRASIL \\ DIEGO.WANDER@PUCRS.BR \\ RUDIMAR BALDISSERA \\ UNIVERSIDADE FEDERAL DO RIO GRANDE DO SUL \\ PORTO ALEGRE, RIO GRANDE DO SUL, BRASIL \\ RUDIMAR.BALDISSERA@UFRGS.BR
}




\section{DINÂMICAS DE RISCOS E CRISES EM CONTEXTOS DE (IN)VISIBILI- DADE NAS MÍDIAS SOCIAIS}

Resumo: Nosso objetivo é apresentar perspectivas e abordagens que reflitam sobre riscos e crises nas mídias sociais, associadas à noção de (in)visibilidade. Para a revisão do estado da arte, recorremos à Teoria Fundamentada em Dados, proposta por Wolfswinkel, Furtmueller e Wilderom (2013). Os achados revelam dinâmicas e características da circulação de sentidos e da movimentação dos públicos nas mídias sociais.

Palavras-chave: Comunicação organizacional; Crises; Mídias Sociais.

\section{DINÁMICA DE RIESGOS Y CRISIS EN CONTEXTOS DE (IN) VISIBILI- DAD EN LAS REDES SOCIALES}

Resumen: Nuestro objetivo es presentar perspectivas y enfoques que reflejen los riesgos y las crisis en las redes sociales, asociado con la noción de (in) visibilidad. Para una revisión del estado del arte, recurrimos a la Grounded Theory, propuesta por Wolfswinkel, Furtmueller y Wilderom (2013). Los resultados revelan dinámicas y características de la circulación de significados y los movimientos de los públicos en las redes sociales.

Palabras Clave: Comunicación Organizacional; Crisis; Redes Sociales.

\section{DYNAMICS OF RISKS AND CRISES IN CONTEXTS OF (IN) VISIBILITY IN SOCIAL MEDIA}

Abstract: Our goal is to present studies that reflect about risks and crises in social media, associated with the notion of (in)visibility. For a review of the state of art, taken from the Grounded Theory, proposed by Wolfswinkel, Furtmueller and Wilderom (2013). The findings reveal dynamics and characteristics of the circulation of meanings and the movements of audiences in social media.

Keywords: Organizational Communication; Crises; Social Media. 


\section{REFLEXÕES INICIAIS E OBJETIVO DO ARTIGO}

O desenvolvimento dos meios de comunicação, sobretudo com a disseminação da internet, permitiu que sujeitos que não dividem um contexto espaço-temporal tenham acesso à mesma informação. Trivinho (2010) descreve esses cenários como a "condição glocal de massa" e a "condição glocal interactiva da vida humana", caracterizados ao, mesmo tempo, por um comportamento nômade e sedentário. Dito de outro modo, os sujeitos conseguem transitar para além do espaço geográfico que ocupam, ainda que estejam "parados".

A acessibilidade a ações e acontecimentos, portanto, deixa de estar centrada na partilha de um mesmo espaço. Isso impacta, sobretudo, na organização de nossa vida social cotidiana e gera condições para o que Thompson (2002) denomina como "quase-interações midiáticas". A expressão evidencia que o processo de fazer circular materiais simbólicos significa disponibilizar algo cujo potencial de acesso é indefinido, dada a gama de interlocutores possíveis.

Segundo Lasta (2015, p.56), a "[...] visibilidade midiática transforma o domínio público em fluxos de informações que concorrem pela 'atenção”". Desse modo, alcançar patamares de visibilidade está relacionado a ocupar o centro da cena no âmbito público e ao êxito nas disputas que se estabelecem nesses espaços na busca pelos holofotes, entre os diversos sujeitos enunciadores. Trivinho (2010) define esse desejo como uma necessidade compulsiva de aparecer, um "imperativo da presença mediática" que se estabelece como um "capital social compulsório", de modo que os esforços se voltem à projeção de si.

Atualmente, as mídias sociais são as expressões mais incidentes e reveladoras dessas características e dinâmicas. Tratam-se de possibilidades, como Facebook, Instagram e Twitter, que permitem o estabelecimento de relações, ainda que a ênfase esteja no compartilhamento de conteúdos, sejam eles textos, vídeos ou imagens. Denominadas por Recuero (2009) como sites de redes sociais, elas figuram de maneira crescente dentre os meios/ canais de comunicação/interlocução utilizados pelas organizações para tentarem se relacionar com os públicos de interesse.

Optamos por dirigir nossos olhares às mídias sociais neste artigo, diante da relevância que assumiram para muitas organizações. Silva (2007) observa que, talvez, no contexto da democratização e do avanço da comunica- 
ção, as Tecnologias de Informação e Comunicação (TICs) representam as maiores possibilidades e, igualmente, os maiores riscos à sociedade. Para Baldissera, Kaufmann e Sartor (2013), elas adquiriram caráter de centralidade na contemporaneidade e são capazes de redimensionar aspectos econômicos, sociais, culturais, psíquicos etc. Dessa forma, os autores alertam que "as organizações são desafiadas a reorganizarem-se frente aos novos processos de construção de visibilidade e imagem-conceito', configuração das relações de poder e formação de opinião" (Ibidem, p.11).

As possibilidades dos usos das mídias sociais são diversas. Os públicos e as organizações passam a poder dialogar em condições mais próximas, no que se refere à possibilidade de emitir opiniões e visibilizar discursos, pareceres e impressões. Isso pressupõe, no contexto das organizações, tomadas de decisão ponderadas e olhares atentos a oportunidades, mas também a riscos e periculosidades, que podem emergir a partir de interações desencadeadas, ou mesmo pela ausência de trocas. "As mídias sociais, em minutos, conseguem disseminar assuntos que antes se mantinham restritos ou se espalhavam morosamente, o que impõe às organizações olhar estratégico, monitoramento e política de atuação" (SILVA, 2012, p.27).

Tal assertiva ganha ainda mais relevância pelo poder de mobilização exponencial que caracteriza as mídias sociais (MARTINO, 2015; CASTELLS, 2013). Isso nos leva a pensar nas interfaces entre a presença das organizações nesses espaços e o desenvolvimento de riscos e crises. Assim, as mídias sociais são fonte de inquietação para as organizações, que, por vezes, têm suas práticas questionadas por grupos que se constituem e se movimentam nessas ambiências. Estas possibilidades de (in)visibilidade vêm se mostrando protagonistas quando da eclosão de escândalos e grandes crises, pois, cada vez mais, esses escândalos e essas crises aparecem associados às formas midiáticas de comunicação, o que potencializa o alcance de eventos que, em outros contextos, poderiam não desfrutar da visibilidade que hoje

1 Segundo Baldissera (2008, p.198), “imagem-conceito” pode ser definida como “[...] um constructo simbólico, complexo e sintetizante, de caráter juridicativo/caracterizante e provisório realizada pela alteridade (recepção) mediante permanentes tensões dialógicas, dialéticas e recursivas, intra e entre uma diversidade de elementos-força, tais como as informações e as percepções sobre a entidade (algo/alguém), o repertório individual/social, as competências, a cultura, o imaginário, o paradigma, a psique, a história e o contexto estruturado". 
adquirem² (THOMPSON, 2002). Quando visibilizadas, as crises passam a ser acessíveis a milhares e até milhões de pessoas.

Nesse sentido, "a visibilidade criada pela mídia pode se tornar a fonte de um novo tipo distinto de "fragilidade"' (THOMPSON, 2007, p.28), de potencial de risco e de constituição de crises. Bruno (2004, p.120) vem ao encontro dessas assertivas ao dizer que "[...] nem toda visibilidade é almejada e requerida. Os dispositivos eletrônicos de vigilância representam muitas vezes a face negativa e potencialmente perversa da visibilidade, inspirando temores de atentados à privacidade e à liberdade".

Tais reflexões nos inquietam e nos motivam a apresentar perspectivas e abordagens que reflitam sobre riscos e crises nas mídias sociais, associadas às noções de (in)visibilidade. Esse, então, é o objetivo do estudo. No Brasil, essas discussões são incipientes, no que tange ao campo científico e com capacidade crítica. A lógica da performance, expressão usual no mercado, e da busca dirigida exclusivamente à visibilidade é preponderante no discurso vigente, embora as tensões dessas "arenas" evidenciem outros interesses, posto que nem sempre são espaços confortáveis e de ratificação dos posicionamentos ${ }^{3}$ desejados pelas organizações. Cabe observarmos ainda o fato de que empregamos a expressão "(in)visibilidade" para frisar o tenso jogo entre o estar (desejar estar e/ou ser cobrado para estar) visível, ao mesmo tempo em que isso possa causar transtornos quando a "luz" que recai sobre as organizações/sujeitos que adentram os espaços de visibilidade não estiver naquilo que desejam manifestar e/ou a que desejam se associar. Para a revisão do estado da arte, conforme objetivo deste trabalho, recorremos à Teoria Fundamentada em Dados, proposta metodológica desenvolvida por Wolfswinkel, Furtmueller e Wilderom (2013), o que detalhamos a seguir.

\section{PROCEDIMENTOS DE REVISÃO DA LITERATURA}

Do ponto de vista metodológico, recorremos à Teoria Fundamentada

2 Partimos do pressuposto de que um acontecimento não visibilizado sequer se constitui em um escândalo, mas a problemática aqui é de que as mídias, dentre elas a internet, fornecem oportunidades que redimensionam o alcance e a escala dos impactos.

3 O termo é bastante comum, especialmente nos estudos de marketing. Neste artigo, destacamos que a perspectiva que nos orienta ao falarmos de posicionamento é a de que esse se constitui na ação de tentar projetar a "imagem-conceito" (BALDISSERA, 2008) desejada junto aos públicos de interesse. 
nos Dados ${ }^{4}$, proposta por Wolfswinkel, Furtmueller e Wilderom (2013). Segundo os autores, é raro que as pesquisas explicitem, com clareza, os procedimentos executados, o que dificulta a replicação dos estudos e permite questionar, inclusive, a confiabilidade do estado da arte apresentado. No intuito de não incorrer nesse problema, a Teoria Fundamentada em Dados é "entendida como um guia, para ajudar na sistematização do processo de revisão, com fins a um melhor resultado, que contribua para o avanço teórico" (Ibidem, p.47)5.

O processo dessa proposta metodológica é composto por cinco etapas. Neste artigo, executamos três delas, intituladas "definir", "pesquisar" e "selecionar", suficientes para estabelecer um panorama das produções que tratam sobre a temática. Em relação à primeira fase da análise, a "definição" - escolha do escopo de pesquisa - optamos por recorrer à plataforma ProQuest ${ }^{6}$, uma vez que essa se propõe a reunir produções científicas em nível internacional e centraliza conteúdos com alto grau de relevância (PROQUEST, 2019).

Essa é uma decisão importante, pois, ao partir para uma base de dados global, conseguimos ter clareza sobre como o assunto é tratado em outros contextos. Evidentemente, a referida base de dados assume critérios de relevância e cientificidade, o que pode excluir do processo estudos relevantes do ponto de vista do conteúdo, mas que não se enquadram nas parametrizações definidas pela plataforma.

Ao entrar na base de dados, aplicamos o filtro Ciências Sociais, por ser a grande área a qual nos filiamos, e optamos produções revisadas por especialistas e periódicos acadêmicos e científicos. Fizemos cerca de quarenta testes para chegar aos termos aplicados. As combinações utilizadas na pesquisa estão no Quadro 1.

4 Tradução do termo original para a Língua Portuguesa. Em inglês, Grounded Theory. $5 \quad$ No original: We would like to emphasize that this method is intended as a guide, to help systematize the reviewing process for a more optimal outcome that contributes to theoretical progress (WOLFSWINKEL, FURTMUELLER E WILDEROM, 2013, p.47).

6 “É um serviço agregador de publicações eletrônicas, que oferece acesso ao texto integral através de uma interface única e online" (PROQUEST, 2019). Nessa plataforma, estão disponíveis mais de cinco mil periódicos, jornais e revistas científicas. 
Quadro 1: Termos e combinações da pesquisa na ProQuest.

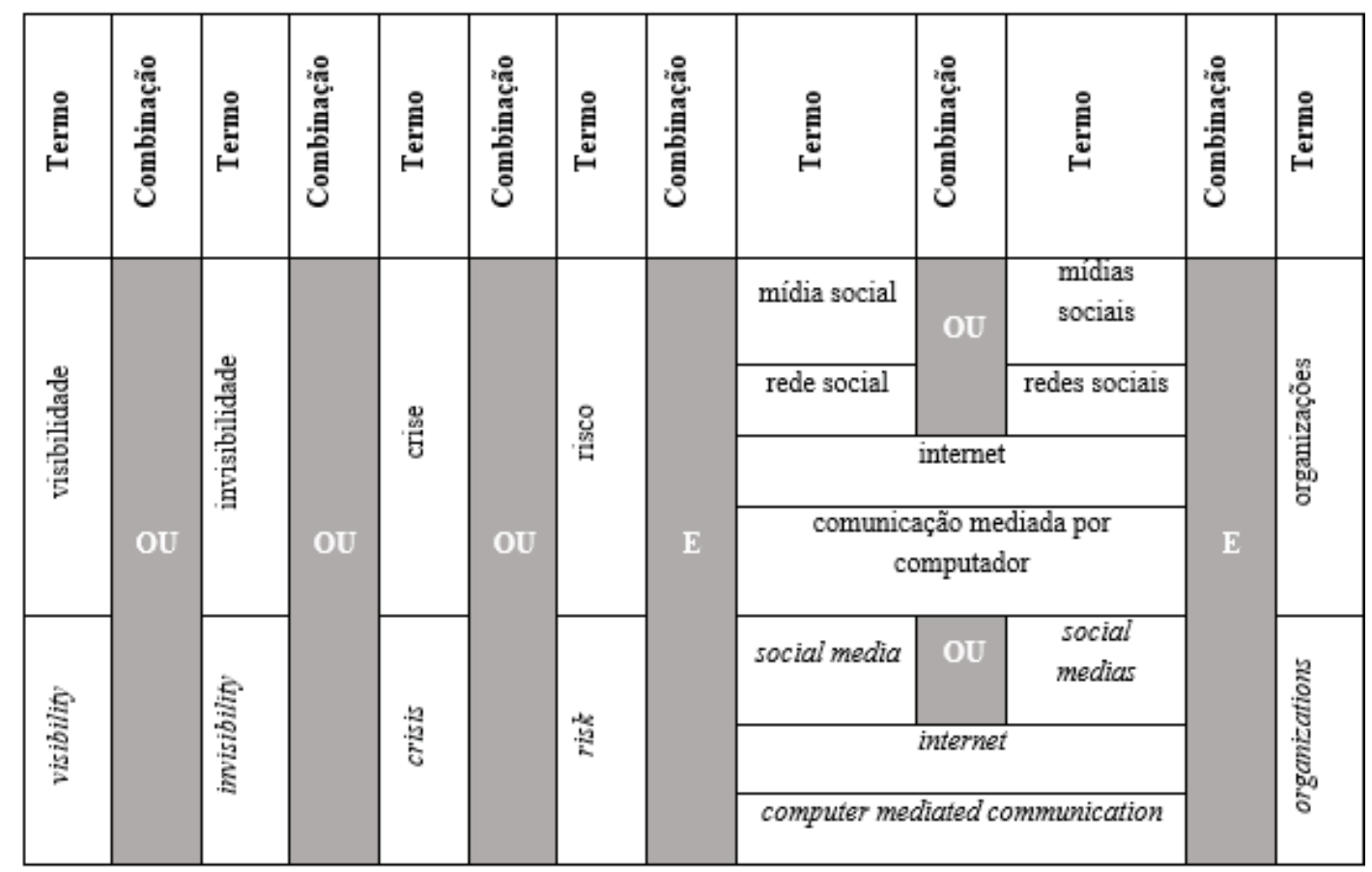

Fonte: elaborado pelo autor, com base em ProQuest (2019).

Conforme indica o Quadro 1, optamos por realizar a pesquisa em duas línguas (Portuguesa e Inglesa), pois os testes nos sinalizaram que os resultados seriam mais amplos. Para evitar a exclusão por entendimentos conceituais divergentes, criamos alternativas que sinalizassem que os estudos envolvem práticas de (in)visibilidade, riscos e crises nas mídias sociais ou, minimamente, na internet ${ }^{7}$.

Além da combinação <OU>, já mencionada, utilizamos a expressão $<\mathrm{E}>$ para indicar que algum dos termos mencionados deveria aparecer no resultado da pesquisa. A palavra <organizações> contribuiu para o refinamento, pois os resultados preliminares apresentavam abordagens, especialmente, na perspectiva da Antropologia, da Psicologia e da Sociologia, que foram entendidas como distantes do escopo desta revisão, a partir de nossa leitura dos resumos dos artigos mapeados nessas áreas.

Passando para a etapa "pesquisar", aplicamos os pressupostos recém descritos. Excluindo as duplicações de resultados, chegamos a 70 artigos. Não encontramos produções em Língua Portuguesa a partir dos pressupostos adotados. Predominam publicações em Língua Inglesa, 68 artigos,

$7 \quad$ A partir dos testes, incluímos a expressão inglesa <computer mediated communication > e sua tradução, uma vez que a plataforma indicou que se constituía em uma alternativa relevante e incidente. 
que representam 97,14\% do total de publicações.

Quadro 2: Resultados das etapas da Teoria Fundamentada nos Dados.

\begin{tabular}{|c|c|c|c|c|}
\hline Título & Autores & Publicação & Ano & País \\
\hline $\begin{array}{l}\text { Emotional stakeholders as } \\
\text { "crisis communicators" in } \\
\text { social media: The case of the } \\
\text { Telenor customer complaints } \\
\text { crisis }\end{array}$ & $\begin{array}{l}\text { Britt Foget } \\
\text { Johansen; } \\
\text { Winni } \\
\text { Johansen; } \\
\text { Nina M. } \\
\text { Weckesser }\end{array}$ & $\begin{array}{l}\text { Corporate } \\
\text { Communications }\end{array}$ & 2016 & Dinamarca \\
\hline $\begin{array}{l}\text { How publics react to crisis } \\
\text { communication efforts: } \\
\text { Comparing crisis response } \\
\text { reactions across sub-arenas }\end{array}$ & $\begin{array}{l}\text { W. Timothy } \\
\text { Coombs; } \\
\text { Sherry Jean } \\
\text { Holladay }\end{array}$ & $\begin{array}{l}\text { Journal of } \\
\text { Communication } \\
\text { Management }\end{array}$ & 2014 & $\begin{array}{l}\text { Estados } \\
\text { Unidos }\end{array}$ \\
\hline $\begin{array}{l}\text { Managing the social } \\
\text { amplification of risk: a } \\
\text { simulation of interacting } \\
\text { actors }\end{array}$ & $\begin{array}{l}\text { J. S. Busby; } \\
\text { S. Onggo }\end{array}$ & $\begin{array}{l}\text { The Journal of the } \\
\text { Operational } \\
\text { Research Society }\end{array}$ & 2013 & Inglaterra \\
\hline $\begin{array}{l}\text { Network technologies for } \\
\text { information warfare and } \\
\text { manipulation of public opinion }\end{array}$ & $\begin{array}{l}\text { O. V. } \\
\text { Syuntyurenk } \\
\text { o }\end{array}$ & $\begin{array}{l}\text { Scientific and } \\
\text { Technical } \\
\text { Information } \\
\text { Processing }\end{array}$ & 2015 & Rússia \\
\hline $\begin{array}{l}\text { Opinion Formation and the } \\
\text { Collective Dynamics of Risk } \\
\text { Perception }\end{array}$ & $\begin{array}{l}\text { Mehdi } \\
\text { Moussaïd }\end{array}$ & PLoS One & 2013 & Alemanha \\
\hline $\begin{array}{l}\text { Perceived risks and risk } \\
\text { management of social media in } \\
\text { an organizational context }\end{array}$ & $\begin{array}{l}\text { Juha } \\
\text { Munnukka e } \\
\text { Pentti Järv }\end{array}$ & $\begin{array}{l}\text { Electronic } \\
\text { Markets }\end{array}$ & 2014 & Finlândia \\
\hline Risk, Crisis, and Social Media & $\begin{array}{l}\text { Joel } \\
\text { Rasmussen } \\
\text { \& Øyvind } \\
\text { Thlen }\end{array}$ & Nordicom Review & 2017 & Noruega \\
\hline
\end{tabular}

Fonte: elaborado pelo autor, com base em ProQuest (2019).

A origem das publicações (Alemanha, Dinamarca, Finlândia, Estados Unidos, Inglaterra, Noruega e Rússia) demonstra a predominância europeia desses estudos. Os artigos foram publicados no período de cinco anos, entre 2013 e 2017. Vale destacar que há mais incidência entre os anos de 2013 e 2014, que concentram quatro artigos. Nesse momento, parece-nos oportuno comentar que o resultado da aplicação das etapas sinaliza a incipiência de pesquisas que tratem dessas questões, o que nos motiva a contribuir para a superação de uma lacuna de estudo e investigação no campo da comunicação organizacional. 


\section{ACHADOS DA REVISÃO TEÓRICA}

A partir daqui nos atemos à socialização das produções mencionadas, para compreendermos que abordagens e perspectivas vêm sendo assumidas sobre riscos e crises nas mídias sociais, associadas às noções de (in)visibilidade. A ênfase dos comentários está nas contribuições que nos parecem mais significativas a este assunto, o que justifica que alguns artigos recebam mais detalhamento que outros.

Em uma das produções que analisamos, Johansen, Johansen e Weckesser (2016), pesquisadores dinamarqueses, revelam nuances importantes sobre como um assunto é potencializado, e em que níveis, nas mídias sociais. $O$ artigo trata especificamente sobre o modo como movimentações de grupos e articulações e disputas em fóruns de discussões interferem/incidem nas percepções dos públicos. Os resultados que apresentam decorrem do acompanhamento de uma crise que se estabeleceu na mídia social Facebook, em 2012, no contexto da presença digital de uma organização do setor de telecomunicações, quando perceberam a existência do que denominaram faith-holders.

A fim de entendermos o que representa essa expressão, recorremos à Luomo-aho (2015). Ela afirma que há três tipos distintos de públicos em situações de risco e crise: 1) os faith-holders, que costumam defender a organização e ratificar seu posicionamento - podem ser nominados como "defensores de fé de uma marca/organização"; 2) os hate-holders, que, ao contrário, embatem e questionam as práticas organizacionais, geralmente sob ótica pessimista e negativa; e, 3) os fake-holders, que são perfis falsos produzidos por astroturfing ${ }^{8}$ ou a partir da criação de perfis gerados por softwares que atuem como faith-holders ou hate-holders.

Em seus estudos, Johansen, Johansen e Weckesser (2016) analisaram 4.368 postagens de clientes atuais (à época), antigos e de companhias rivais da organização. Os principais aprendizados envolvem a noção de que as falas autorizadas, institucionais, são complementadas pelos sentidos ofertados pelos faith-holders, o que é bastante oportuno à organização que vive

8 O conceito surge no contexto político americano, na década de 1980, e evidencia a recorrência a grupos de pessoas que expressam opiniões aparentemente genuínas, mas que decorrem de motivações de outra ordem (HOGGAN, 2006). São "estratégias complexas formuladas para criar a impressão de que existe um público se manifestando como uma forma de influenciar a opinião pública" (SILVA, 2013, p.15). 
uma crise. A descoberta que mais se destaca, porém, é que o tom de comunicação e o papel assumido pela organização e pelos "defensores da marca" não são iguais. Os faifh-holders empregam "estratégias de respostas defensivas", enquanto a organização recorre a "respostas acomodativas". Ou seja, os públicos se expõem e adotam posturas agressivas e que evidenciam o envolvimento emocional com as críticas. A organização, por outro lado, evita a adoção de posturas agressivas. Os faifh-holders, assim, se mostram "úteis", o que sugere que as organizações precisam ter clareza de quem são esses interlocutores e invistam em práticas de relacionamento sistemático com tais pessoas, pois elas são bastante incidentes no que tange aos rumos e sentidos assumidos nas interações sociais.

O artigo de Coombs e Holladay (2014) também apresenta importantes resultados. Nesse texto, os pesquisadores americanos analisaram as reações dos públicos em situações de crise, a partir de diferentes estímulos e mensagens veiculadas em portais de conteúdo. Chamam atenção para três pontos: a) é fundamental monitorar os diversos espaços em que uma situação-problema está sendo discutida, a fim de criar parâmetros de como mensagens visibilizadas pelas organizações (ou que as envolvam) são percebidas. Assim, é possível prognosticar possíveis impactos e desenvolver iniciativas e assumir comportamentos que partam dessas tendências; $b$ ) ter uma reputação consistente é fundamental para que os impactos de uma crise sejam revertidos com mais celeridade. Organizações que detém esse "crédito de confiança" têm, a priori, essa vantagem, o que foi comprovado nos estudos de Coombs e Holladay (Ibidem); c) as organizações têm a probabilidade de obter melhores resultados quando desenvolvem espaços diversos para tratar de uma crise, seja em portais próprios ou em outras ambiências da internet. Assim, criam "subarenas" que ajudam a retirar a ênfase de um único ambiente. Com isso, é possível adaptar as mensagens gerais às expectativas e necessidades de grupos com perfis de comportamentos diversos, o que pode se tornar mais acertado a partir do que comentamos no item "a". Isso tende a enfraquecer a visibilidade de assuntos críticos, pois fragmenta as percepções sobre a relevância do acontecimento.

Busby e Onggo (2013), por sua vez, nos ajudam a compreender o modo como um risco é amplificado nas mídias sociais, a partir do comportamento dos públicos. Portanto, aqui, a noção de risco não é discutida pela ótica da organização, mas dos sujeitos que habitam esses espaços. O estudo inglês comprova que, à medida que o relato de um acontecimento vai se dissemi- 
nando, as apropriações acabam indo para campos subjetivos e gerando impressões/leituras diversificadas. Assim, se afastam daquilo que efetivamente ocorreu, assumindo os vieses diversos que são incorporados aos relatos. Há dois possíveis impactos decorrentes desse cenário: em primeiro lugar, as percepções, pautadas por relatos predominantemente simplistas, rumam a posições polarizadas; e, em segundo, é provável que isso gere um clima de ansiedade acerca de quem vai sendo impactado pelos relatos, o que motiva o aumento do alcance e da disseminação e, logo, da visibilidade que o envolve.

O objeto de estudo dessa investigação abarca as repercussões da gripe aviária na Europa. Um aspecto relevante descrito pelos pesquisadores é que, na medida em que o risco se distancia do contexto de uma pessoa (que não a ameaça), há uma tendência de que esse sujeito consiga buscar outras informações, por vezes mais seguras, e contrapor as falas predominantes - geralmente pautadas pela emoção, pela subjetividade e por argumentos não apurados e confiáveis. Os autores afirmam que, no caso de uma organização que vive uma situação-problema, é importante que ela não limite seu olhar e suas práticas às pessoas mais impactadas, pois são justamente as que não são diretamente atingidas que têm potência para dar visibilidade a outras compreensões da situação. Esse aspecto está diretamente relacionado ao potencial de redução da visibilidade.

Sob a mesma perspectiva de Busby e Onggo (2013), a da avaliação dos públicos sobre um fato, Moussaïd (2013) discute nuances acerca do processo de formação de opinião e como se dá a percepção de risco a partir das dinâmicas coletivas. Para isso, assume a visão dos sujeitos potencialmente impactados por riscos e não das organizações. O pesquisador compreende que as mídias de massa pautam a discussão sobre riscos possíveis/prováveis que, se percebidos como relevantes, como reais ameaças, passam a ser veiculados nos perfis individuais nas mídias sociais. É esse aspecto que os faz ganhar potência, ou não, e em diferentes escalas.

Apesar de os indivíduos serem expostos ao mesmo estilo de informação, as repercussões sempre adquirem vieses que decorrem de dois fatores centrais: a capacidade/propensão dos sujeitos em buscarem informações complementares sobre o risco e a influência social (legitimidade e relevância) de quem dá visibilidade a esses riscos. A partir disso, o autor cria um modelo de como os riscos são percebidos, que apresentamos a seguir (Gráfico 1). 
Gráfico 1: Escala de percepção de risco.

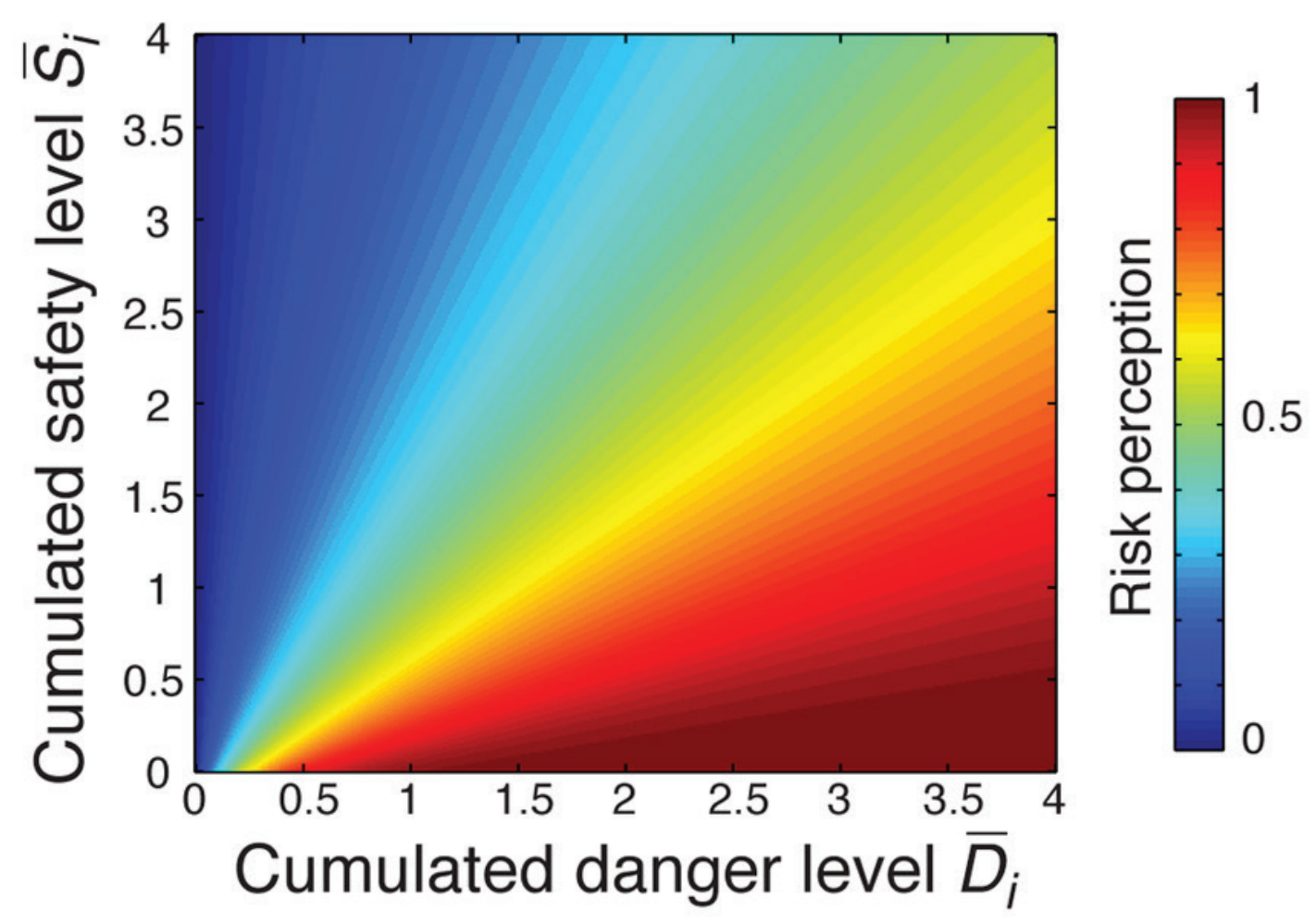

Fonte: Moussaïd (2013).

O eixo vertical envolve o nível de segurança de uma pessoa em relação ao risco, o que passa pelas informações que obteve a partir de suas fontes (independentemente de quais sejam). Esse nível vai de o a 4. Já o eixo horizontal dá conta do perigo associado ao risco - quanto mais alta essa associação, maior a percepção de ameaça do risco. A partir desses dois fatores é possível compreender a "percepção de risco". O nível mais alto ocorre quando um sujeito concebe um risco como de alto nível de periculosidade e não possui informações seguras sobre ele. Em situações nas quais um risco é percebido da mesma forma, mas o indivíduo tem acesso a informações críveis, a percepção do risco cai para a metade da escala (2.5).

Esse aspecto revela quão fundamentais são as informações oficiais em situações nas quais uma organização deseja direcionar a visibilidade sobre algo e diminuir a repercussão de um assunto que não lhe interessa. A partir dessa escala, também podemos pensar que qualquer nova informação veiculada sobre uma situação de risco pode impactar o modo como é percebida, pois tem o potencial de reorganizar os (des)entendimentos dos sujeitos.

Syuntyurenko (2015), pesquisador russo, investiga como as informações visibilizadas na internet podem manipular a opinião pública. Do ponto de vista de cenário, o autor alerta o que está percebendo na última década: a) o 
desenvolvimento de estruturas de mídias sociais destrutivas, tendo em vista a falta de controle acerca da veracidade das informações visibilizadas; e, b) a criação de recursos para que as organizações possam promover ataques de informação e de desinformação/contrainformação de interlocutores. O pesquisador usa o termo "media viruses" para se referir ao potencial destrutivo de informações falsas veiculadas na internet, sobretudo nas mídias sociais, com o propósito de mover as pessoas a assumir essas mensagens como verdadeiras, causando problemas sociais sérios e consequências ainda indeterminadas e imprecisas.

Ele também reforça como a produção dos conteúdos veiculados nesses espaços são produzidos por poucas pessoas. Recorre a dados do Twitter para reiterar sua fala: nessa mídia social, $2 \%$ dos usuários criam $60 \%$ de todo o conteúdo que é distribuído, o que o faz questionar quão democráticos são esses espaços. Para finalizar essas questões, sinaliza que a internet e as mídias sociais vêm se tornando um "instrumento" global de guerra psicológica e manobra de movimentos sociais, o que o faz chamar atenção para o potencial destrutivo desses recursos tecnológicos.

Por fim', temos o artigo Risk, Crisis, and Social Media, de Rasmussen e Ihlen (2017). Segundo os autores, as mídias sociais têm recebido uma significativa atenção de pesquisadores que se dedicam a compreender os riscos que permeiam as organizações. Isso é ainda mais incidente dentre aqueles que definem os riscos como "transfronteiriços"10 (tradução nossa), ou seja, que as origens e os efeitos das possíveis situações-problema atravessam/ ignoram fronteiras funcionais, nacionais e culturais.

Rasmussen e Ihlen (2017) destacam que há de se atentar para a fragilidade de discursos que indicam que as mídias sociais são totalmente igualitárias e que promovem o acesso a olhares diversos e diversificados. Endossam a afirmação do seguinte modo: "Estudos empíricos mostram fortes padrões

9 Ainda há o artigo Perceived risks and risk management of social media in an organizational context, desenvolvido na Finlândia, por Munnukka e Järvi (2014), que analisa como as organizações finlandesas vêm limitando a expressividade nas mídias sociais em função de dificuldades que as impedem de qualificar tal presença e o relacionamento com os públicos. O estudo, então, apresenta e discute os "empecilhos" apreendidos como mais relevantes, bem como os procedimentos de controle adotados. Se comparado ao Brasil, por exemplo, eles revelam um perfil bastante incipiente da presença das organizações nas mídias sociais. Por isso, aqui, optamos por apenas referir o artigo sem destacar seus resultados em mais profundidade. 
de homofilia nas mídias, em que as elites seguem as elites, enquanto os cidadãos "comuns" raramente recebem atenção" (Ibidem, p.2). Portanto, as oportunidades de visibilidade não são iguais, embora haja a percepção de que as mídias sociais se constituam em espaços, por suas especificidades, horizontais e democráticos.

Esses pesquisadores realizaram uma investigação das publicações sobre riscos e mídias sociais publicadas nos Estados Unidos entre 2009 e 2015. O corpus de análise foi constituído a partir da pesquisa de artigos e produções científicas, em bancos de dados ${ }^{11}$, e resultou em 150 publicações. Em termos de volume, o Gráfico 2 sinaliza como esses estudos vêm ascendendo, concomitante ao crescimento da relevância das mídias sociais:

Gráfico 2: Resultados de produções científicas que tratam sobre riscos e mídias sociais (e termos correlatos), nos Estados Unidos.

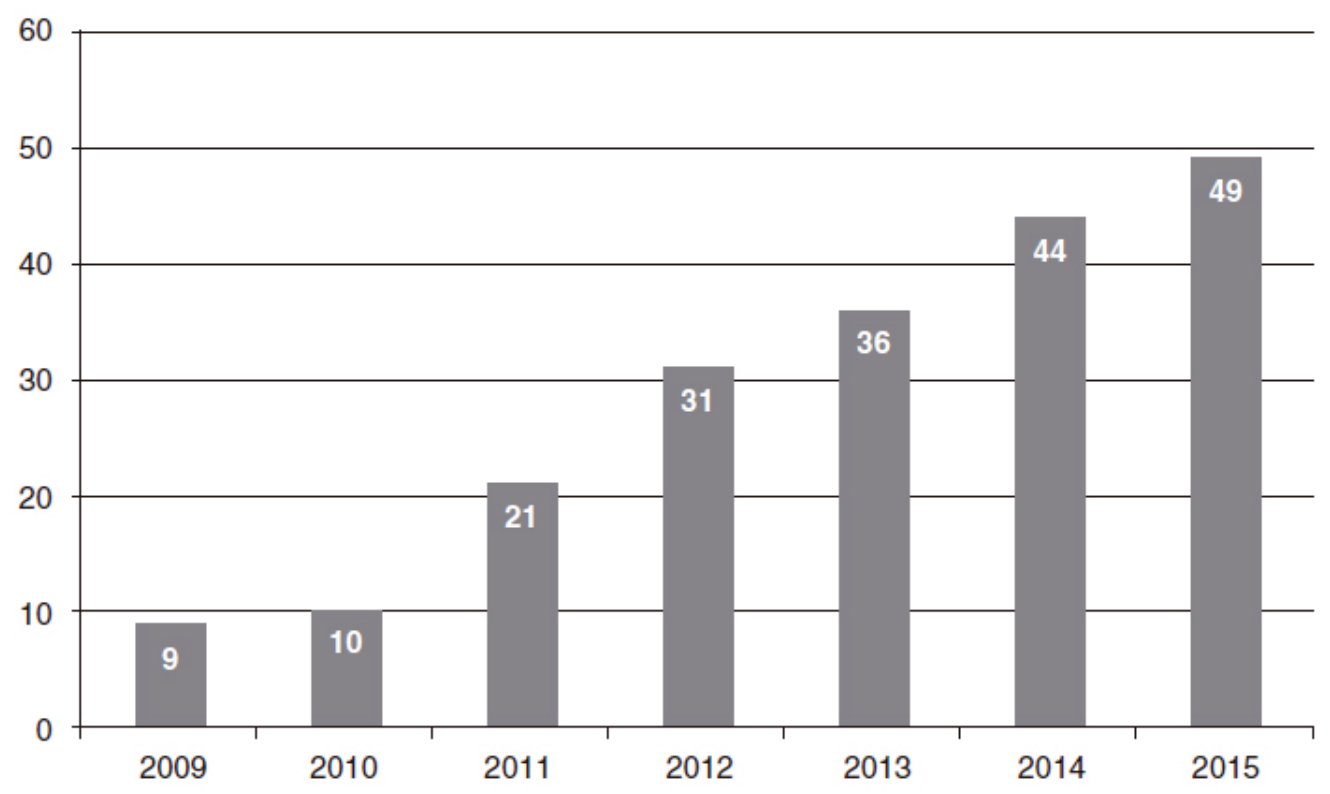

Fonte: Rasmussen e Ihlen (2017, p.6).

Algo que nos parece relevante é que os estudos se concentram em torno de crises já estabelecidas, nas iniciativas adotadas quando algo demanda uma posição reativa das organizações. Ao analisarem o que cada publicação

11 Rasmussen e Ihlen (2017) combinaram as palavras "internet”, "online”, "social media", "Facebook", "Twitter", "YouTube”, "blog” ou "Instagram” à "risk” (risco), "crisis" (crises) ou "disaster" (desastres) para chegar aos resultados. Em função da solidez da pesquisa e da revisão realizada, há uma contribuição significativa desses autores neste tópico. 
se propunha a analisar, os atures chegaram a três agrupamentos: "cenários de crise autêntica", "cenários de risco autêntico" e "cenário fictício/experimental". Vejamos o Gráfico 3:

Gráfico 3: Agrupamento das publicações por escopo do estudo.

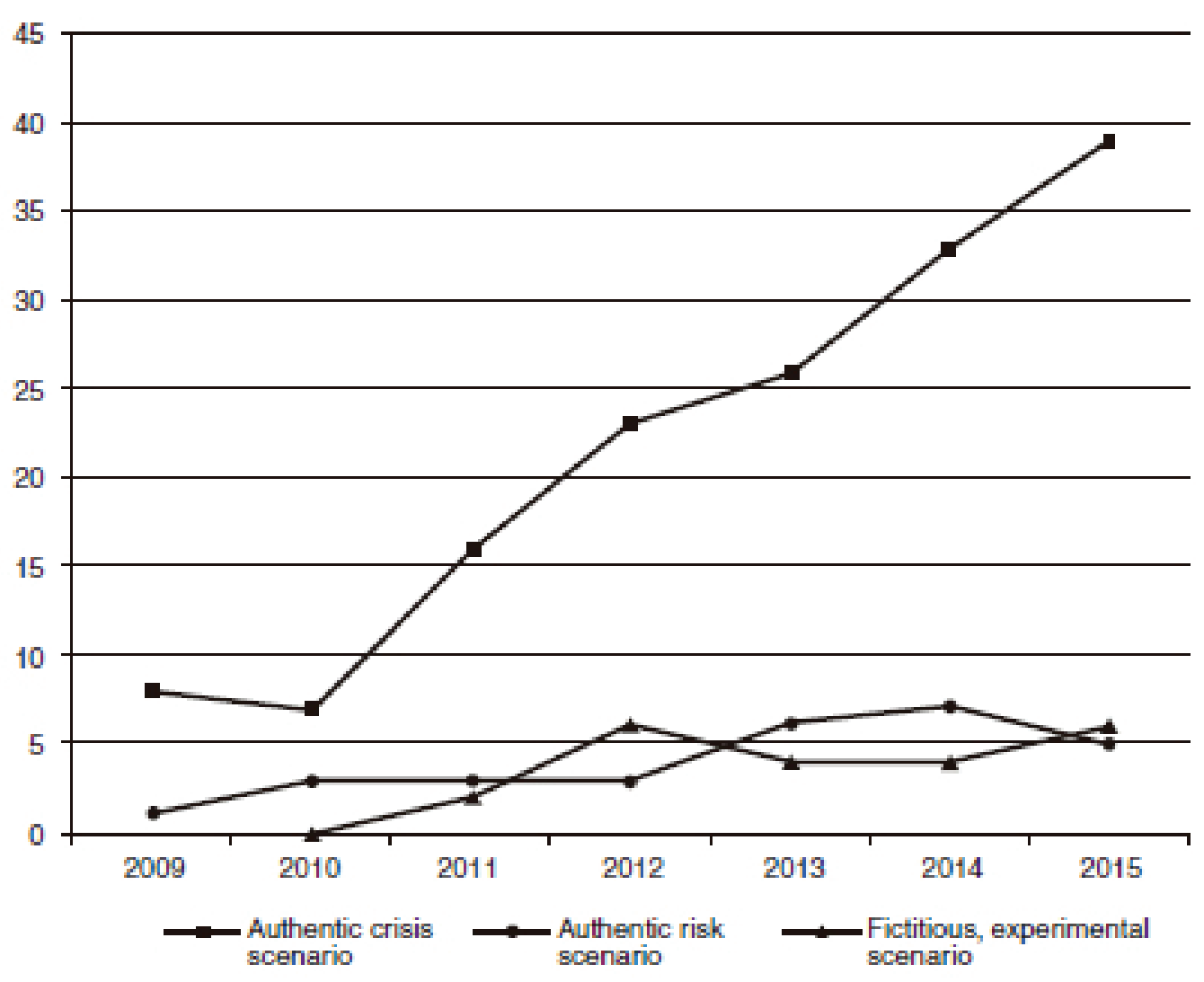

Fonte: Rasmussen e Ihlen (2017, p.7).

Rasmussem e Ihlen (2017) destacam que apenas em 2011 têm início os estudos previsivos com fins a simular e identificar padrões de comportamento em cenários de risco. Um dos resultados sinalizou que conteúdos assinados pela liderança de uma organização tendem a repercutir mais do que se eles forem genéricos (sem assinatura do/a líder). Com esse conhecimento apreendido, podemos pensar que a decisão de assinar, ou não, um comunicado divulgado nas mídias sociais passa a ser relevante e um "recurso" que pode indicar o potencial de mais ou menos visibilidade.

As descobertas dos autores (Ibidem) sinalizam que há algumas ênfases nos estudos que revelam percepções sobre benefícios que as organizações podem ter em situações de risco, a partir da presença nestes espaços. São elas: a) é possível identificar pessoas "relevantes" em uma comunidade e (buscar) estabelecer relacionamento - o resultado esperado é que elas su- 
portem, reforcem e legitimem os discursos organizacionais em situações de risco e de crise; b) há a possibilidade de iniciar diálogos que envolvam riscos, antes que eles se tornem crises - as mídias sociais facilitam e dão celeridade à troca de informações e opiniões; c) é possível acompanhar conversas que ocorrem nesses espaços, para mapear tendências, temas e problemas importantes; e, d) em situações em que posicionamentos oficiais precisam ser visibilizados, os conteúdos tendem a ser disseminados de modo mais ágil, se comparado com mensagens usuais e corriqueiras.

Os quatro enfoques podem ser lidos como caminhos de (in)visibilidade em situações de risco e de crises estabelecidas, pois indicam tratamentos que as organizações podem dar a conteúdos que "precisam” gerenciar. Há de se atentar que essas pesquisas se limitam às realidades da América do Norte, da Europa Ocidental e do Leste da Ásia, o que revela a oportunidade de estudar tais fenômenos no contexto do Brasil e da América do Sul.

\section{CONSIDERAÇÕES DA PESQUISA}

Com base no que descobrimos a partir da aplicação da Teoria Fundamentada em Dados, estabelecemos um panorama acerca dos estudos realizados, publicados e reconhecidos mundialmente sobre riscos e crises nas mídias sociais, associados à perspectiva de (in)visibilidade. São investigações disseminadas na condição de reflexões e apontamentos consistentes sobre a temática.

Vimos o quanto são incipientes as produções teóricas que se dedicam a refletir sobre riscos e crises nas mídias sociais, visibilizadas em bases de dados internacionais. Porém, nos deparamos com produções que analisam teoricamente fenômenos empíricos, o que pode indicar a tentativa de assimilação de movimentos nos quais as organizações se veem envolvidas e de dinâmicas nessas ambiências.

Destacamos alguns aprendizados centrais dos estudos mencionados: a) a mitigação dos riscos envolve agilidade na resolução dos encaminhamentos e sistematização das escutas (RASMUSSEN; IHLEN, 2017); b) é oportuno fortalecer relações com faith-holders para que contribuam com as organizações em possíveis situações-problema (JOHANSEN; JOHANSEN; WECKESSER, 2016); c) compreender os impactos das mensagens institucionais (oficiais) visibilizadas pelas organizações em uma situação de crise é importante, a fim de uma revisão constante das estratégias (COOMBS; HOLLADAY, 2014); d) o fomento de múltiplos espaços para abrigar as repercussões 
de uma crise tendem a fragmentar as percepções e enfraquecer o senso de relevância (Ibidem); e) em uma crise, as organizações não devem limitar sua atenção às pessoas mais impactadas - são os demais sujeitos, geralmente mais tolerantes, que podem potencializar outros sentidos sobre a situação (BUSBY; ONGGO, 2013); f) o risco percebido como o mais incidente é aquele em que o interlocutor se vê ameaçado pela situação, associado à falta de informação segura (MOUSSAÏD, 2013); e, g) as mensagens falsas que circulam nas mídias sociais e na internet, de modo geral, assumem protagonismo nas crises - elas são acionadas como mecanismo de desinformação e contrainformação, constituindo cenários de ataques e disputas, no campo simbólico (SYUNTYURENKO, 2015).

Esses, então, são alguns achados decorrentes da revisão de literatura. Fica evidente que os cenários que se entrelaçam com o desenvolvimento das TICs e das mídias sociais predispõem "novas" alternativas de visibilidade e outros olhares sobre o fenômeno da exposição das organizações. A referida falta de controle sobre leituras possíveis e o anseio de abrandar ameaças às "imagens-conceito" desejadas tornam a gestão de riscos e de crises uma pauta ascendente no contexto das discussões sobre comunicação organizacional e, também, uma preocupação cotidiana de gestores e profissionais da área.

Evidentemente, persistem diversos desafios e (in)compreensões no que tange à presença das organizações e à circulação de informações e sentidos nessas ambiências. De qualquer modo, esperamos que as discussões propostas, a partir do referencial coletado, contribuam para o avanço do conhecimento sobre experiências, dinâmicas e estratégias oportunas nas mídias sociais.

\section{REFERÊNCIAS}

BALDISSERA, Rudimar. Comunicação e significação na construção da imagem-conceito. Revista Fronteira, v.10, 2008. pp. 193-200.

BALDISSERA, Rudimar; KAUFMANN, C.; SARTOR, Basilio. Relações Públicas, Comunicação Organizacional e TDCl's: entre a visibilidade e a vulnerabilidade. In: MOREIRA, Elisabeth Ruber; PONS, Mônica (Orgs.). Relações Públicas, tecnologia e públicos. 1 ed. Santa Cruz do Sul, 2013, v. 1, pp. 10-26.

BRUNO, Fernanda. A obscenidade do cotidiano e a cena comunicacional contemporânea. In: Revista Famecos. 2004. V.11, n.25. Disponível em <http://revistaseletronicas. pucrs.br/ojs/index.php/revistafamecos/article/view/3280>. Acesso em: 13 nov. 2019. BUSBY, J.S. ONGGO, S. Managing the social amplification of risk: a simulation of interac- 
CADERNOS DE COMUNICAÇÃO

UNIVERSIDADE FEDERAL DE SANTA MARIA

ting actors. In: Journal of the Operational Research Society. vol 64, pp. 638-653, 2013. Disponível em < https://link.springer.com/article/10.1057/jors.2012.80>. Acesso em: 07 nov. 2019.

CASTELLS, Manuel. Redes de indignação e esperança: movimentos sociais na era da internet. Trad. Carlos Alberto Medeiros. Rio de Janeiro: Zahar, 2013. 271 p.

COOMBS, W. Timothy; HOLLADAY, Sherry Jean. How publics react to crisis communication efforts: comparing crisis response reactions across sub-arenas. In: Journal of Communication Management, vol. 18, pp. 40-57, 2014. Disponível em <https://doi.org/10.1108/ JCOM-03-2013-0015>. Acesso em: 02 fev. 2019.

HOGGAN, James. Astroturf: The Only Grass That Withstands Toxic Friends of Science. DesMogBlog. 2006. Disponível em: <https://www.desmogblog.com/astroturf-the-only-grass-that-withstands-toxic-friends-of-science>. Acesso em: 13 nov. 2019.

JOHANSEN, Britt Foget; JOHANSEN, Winni; WECKESSER, Nina M. Emotional stakeholders as "crisis communicators" in social media: The case of the Telenor customer complaints crisis". In: Corporate Communications: An International Journal, Vol. 21, 2016, pp.289-308. Disponível em <https://doi.org/10.1108/>. Acesso em: 11 nov. 2019.

LASTA, Elisangela. A práxis reflexiva das relações públicas na sociedade midiatizada: mediação estratégica comunicação nos blogs corporativos. 2015. 258g. Tese (Doutorado em Comunicação) - Programa de Pós-Graduação em Comunicação, UFSM, Santa Maria, 2015. Disponível em < http://repositorio.ufsm.br/bitstream/handle/1/3430/LASTA\%2C\%20 ELISANGELA.pdf?sequence=1\&isAllowed=y>. Acesso em: 02 nov. 2019.

LUOMO-AHO, Vilma. Understanding Stakeholder Engagement: Faith-holders, Hateholders \& Fakeholders. 2015. Disponível em <https://instituteforpr.org/wp-content/uploads/updated-vilma-pdf.pdf>. Acesso em: 10 nov. 2019.

MARTINO, Luís Mauro Sá. Teoria das Mídias Digitais: linguagens, ambientes, redes. Petrópolis, RJ: Vozes, 2014. 291 p.

MOUSSAÏD, Mehdi. Opinion Formation and the Collective Dynamics of Risk Perception. In: Plos One, 2013. Disponível em < https://doi.org/10.1371/journal.pone.0084592>. Acesso em: 12 nov. 2019.

MUNNUKKA, Juha; JÄRV, Pentti. Perceived risks and risk management of social media in an organizational context. In: Electronic Markets. Vol. 24, pp.219-229, 2014. Disponível em < https://link.springer.com/article/10.1007/s12525-013-0138-2>. Acesso em: 12 nov. 2019.

PROQUEST. Disponível em <http://www.proquest.com/>. Acesso em: 02 nov. 2019.

RASMUSSEN, Joel; IHLEN, Øyvind. Risk, Crisis, and Social Media. In: Nordicom Review. Vol. 38, 2017. Disponível em <https://doi.org/10.1515/nor-2017-0393>. Acesso em: 15 nov. 2019.

RECUERO, Raquel. Redes sociais na Internet. Porto Alegre: Sulina, 2009. 191p.

SILVA, D.R. O astroturfing como processo comunicativo: enquadramentos na manifestação encenada de um público. In: V Congresso da Compolítica. Curitiba, 2013.

SILVA, Juremir Machado da. Entrevista com Alex Primo [30 ago. 2007]. Porto Alegre: PUCRS, 2007. Entrevista concedida ao Programa Livro Aberto. Disponível em <www. 
alexprimo.com>. Acesso em: 08 jun. 2017.

SILVA, Diego Wander. As mídias sociais no contexto da comunicação digital das universidades brasileiras. 2012. 159f. Dissertação (Mestrado em Comunicação Social) - Faculdade de Comunicação Social, PUCRS, Porto Alegre, 2012. Disponível em <http://repositorio.pucrs.br:8080/dspace/bitstream/10923/2081/1/000438298-Texto\%2bCompleto-0.pdf>. Acesso em: 09 nov. 2019.

SYUNTYURENKO, O. V. Network Technologies for Information Warfare and Manipulation of Public Opinion. In: Scientific and Technical Information Processing. Vol. 42, pp.205-210, 2015. Disponível em < https://link.springer.com/article/10.3103/S014768821504005X>. Acesso em: 14 nov. 2019.

THOMPSON, John B. O escândalo político: poder e visibilidade na era da mídia. Trad. Pedrinho A. Guareschi. Petrópolis, RJ: Vozes, 2002. 325 p.

. A nova visibilidade. Matrizes, v. 1, n. 2, 2007. Disponível em <http://www. revistas.univerciencia.org/index.php/MATRIZes/article/viewArticle/5230>. Acesso em: 05 nov. 2019.

TRIVINHO, Eugênio. Visibilidade mediática, melancolia do único e violência invisível na cibercultura: significação social-histórica de um substrato cultural regressivo da sociabilidade em tempo real na civilização mediática avançada. In: Anais do XIX Encontro Nacional da Compós, Rio de Janeiro, 2010. Disponível em < http://compos.com.puc-rio.br/ media/gt1_eugenio_trivinho.pdf>. Acesso em: 11 nov. 2019.

WOLFSWINKEL, Joost F.; FURTMUELLER, Elf;; WILDEROM, Celeste P. M.; Using grounded theory as a method for rigorously reviewing literature. European Journal of Information Systems. Londres, v. 22, pp.45-55, jan. 2013. Disponível em <http://link.springer.com/article/10.1057/ejis.2011.51>. Acesso em: 02 nov. 2019. 


\section{Diego Wander da Silva}

Doutor em Comunicação e Informação pela UFRGS e docente de Relações Públicas na PUCRS. Membro do Grupo de Pesquisa em Comunicação Organizacional, Cultura e Relações de Poder (GCCOP/UFRGS).

E-mail: diego.wander@pucrs.br

\section{Rudimar Baldissera}

Doutor em Comunicação. Mestre em Comunicação/Semiótica. Na UFRGS, é docente associado do Departamento de Comunicação da UFRGS e pesquisador e professor do Programa de Pós-Graduação em Comunicação. Líder do GCCOP. Bolsista produtividade do CNPq.

E-mail: rudimar.baldissera@ufrgs.br 